\title{
Prostate Cancer in Primary Care
}

\author{
Samuel W. D. Merriel (1) · Garth Funston · Willie Hamilton
}

Received: July 3, 2018 / Published online: August 10, 2018

(C) The Author(s) 2018
Enhanced digital content To view enhanced digital content for this article go to https://doi.org/10.6084/ m9.figshare.6870797.

S. W. D. Merriel $(\bowtie) \cdot$ W. Hamilton

Exeter Medical School, University of Exeter, Exeter, UK

e-mail: s.w.d.merriel@exeter.ac.uk

\section{G. Funston}

Department of Public Health and Primary Care, University of Cambridge, Cambridge, UK crossover in symptoms between prostate cancer and benign conditions affecting the prostate such as benign prostatic hypertrophy (BPH) and prostatitis, making it very challenging to distinguish between them on the basis of symptoms. The evidence for the performance of PSA in asymptomatic and symptomatic men for the diagnosis of prostate cancer is equivocal. PSA is subject to false positive and false negative results, affecting its clinical utility as a standalone test. Clinicians need to counsel men about the risks and benefits of PSA testing to inform their decision-making. Digital rectal examination (DRE) by primary care clinicians has some evidence to show discrimination between benign and malignant conditions affecting the prostate. Patients referred to secondary care for diagnostic testing for prostate cancer will typically undergo a transrectal or transperineal biopsy, where a number of samples are taken and sent for histological examination. These biopsies are invasive procedures with side effects and a risk of infection and sepsis, and alternative tests such as multiparametric magnetic resonance imaging (mpMRI) are currently being trialled for their accuracy and safety in diagnosing clinically significant prostate cancer.

Keywords: Diagnosis; LUTS; Primary care; Prostate cancer; Prostate-specific antigen 


\section{INTRODUCTION}

Prostate cancer is the second most common cancer diagnosed in men globally, after lung cancer. Despite relatively high survival rates for men with prostate cancer, more than 300,000 prostate cancer deaths occurred in 2012 worldwide. Age and family history are key risk factors for prostate cancer, and black men have a higher risk of prostate cancer incidence and death compared to men from white or Asian backgrounds [1].

The majority of cases of prostate cancer are diagnosed in men from western countries in the Americas and Europe, and this has largely been driven by the introduction of prostate-specific antigen (PSA) for prostate cancer detection in the 1990s. The widespread use of PSA has proven controversial as the evidence for benefit as a screening test in asymptomatic men is still subject to debate, and PSA is prone to false positives and false negatives in men with symptoms suggestive of a possible diagnosis of prostate cancer [2]. Work is ongoing to find better ways to risk stratify men for further investigation, and more accurate methods to differentiate between clinically significant and clinically insignificant prostate cancer to inform treatment decisions.

Most prostate cancer diagnoses are made in symptomatic men. Prostate cancer should be suspected in men over 50 years old presenting with lower urinary tract symptoms (LUTS), visible haematuria or erectile dysfunction [3]. LUTS are also a common presenting symptom of benign conditions affecting the prostate, such as benign prostatic hyperplasia (BPH) and prostatitis, creating a diagnostic challenge. There is no strong evidence of association between the severity of LUTS and the likelihood of prostate cancer or the stage at diagnosis [4]. Digital rectal examination (DRE) is recommended in many countries alongside PSA to aid decision-making about referral for diagnostic testing. A recent systematic review suggests that DRE has a high specificity and positive predictive value (PPV) for prostate cancer in symptomatic patients [5].

In light of the limitations of PSA, a number of other tests have been investigated to aid the diagnosis of clinically significant prostate cancer. PSA is a kallikrein serine protease, and other related biomarkers have been assessed for a potential role in prostate cancer detection [6]. Genome-wide association studies (GWAS) have identified more than 100 single nucleotide polymorphisms (SNPs) related to risk of prostate cancer [7]. Multiparametric magnetic resonance imaging (mpMRI) has gained much interest in recent years, both as a diagnostic test for prostate cancer and for monitoring men with localised prostate cancer on active surveillance for signs of disease progression [8].

This article will outline the epidemiology of prostate cancer, an approach to diagnosis, and further investigations and referral criteria. This article is written by general practitioners (GPs) in the UK, but will be of relevance to primary care practitioners working in other healthcare systems. This article is based on previously conducted studies and does not contain any studies with human participants or animals performed by any of the authors.

\section{EPIDEMIOLOGY AND RISK FACTORS}

Approximately 1.1 million men were diagnosed with prostate cancer in 2012 , with over $70 \%$ of these men being from high-income countries. Age-standardised incidence rates are highest in Australia and New Zealand (111.6 per 100,000 men), North America (97.2), and Western Europe (85.8), and lowest in South (4.5) and Western (10.5) Asian regions. Prostate cancer is the fifth leading cause for cancer death in men worldwide, with the highest mortality rates in countries with predominantly black ethnic populations such as the Caribbean (29 per 100,000 males) and Africa (19.9) [1]. Mortality rates from prostate cancer have generally decreased globally in the last decade, with the exception of a few Northern European and Asian countries [9].

Prostate cancer incidence relates strongly to age, with age-specific incidence rates rising sharply from the age of 50 years and being highest in men aged 90 and above, according to 
Office for National Statistics data from the UK [10]. A positive family history significantly affects a man's risk of prostate cancer. Pooled risk estimates suggest that a man with one firstdegree relative (father or brother) with a diagnosis of prostate cancer has a relative risk of 2.48 (95\% CI 2.25-2.74), rising to 4.39 (95\% CI 2.61-7.39) for men with two or more first-degree relatives affected by the disease [11]. The evidence for an association between prostate cancer and heritable germline mutations such as BRCA1 [12,13] and Lynch syndrome [14] is more mixed.

Men from African and Caribbean ethnic backgrounds have the highest prostate cancer incidence and mortality rates compared to other ethnic groups. The lifetime risk of prostate cancer in black UK men is double that of white UK men and three times the risk of men from Asian backgrounds [15]. Relative to white men, men of African or Caribbean descent have a worse prognosis in the USA [16] and the UK [17]. There are no known modifiable risk factors for prostate cancer.

\section{SYMPTOMS AND SIGNS}

Prostate cancer is detected in men in a number of ways. The widespread use of PSA as a screening test for prostate cancer in some countries has led to increasing diagnoses being made in asymptomatic men. Men may present to their doctor complaining of LUTS or other genito-urinary symptoms, and are thus investigated for prostate cancer. It also is suspected that there are a significant number of men who go through life and die with undiagnosed prostate cancer; this suspicion is based on the findings of autopsy studies showing that up to three quarters of men over the age of 85 had neoplastic changes in the prostate, not all of whom had been diagnosed prior to their death [18].

LUTS are very common as men get older, with studies estimating a prevalence of greater than $50 \%$ in men aged 50 years and above, increasing further with increasing age [19]. LUTS are broadly divided into three categories: storage, voiding, and post-micturition symptoms (see Table 1). LUTS are generally associated with possible
Table 1 Categories of LUTS. Adapted from [20]

\begin{tabular}{ll}
\hline LUTS category & Symptoms \\
\hline Voiding & Poor stream \\
& Intermittent stream \\
& Hesitancy \\
& Straining to void \\
& Terminal dribbling \\
Storage & Frequency \\
& Nocturia \\
& Urgency \\
Post-micturition & Urge incontinence \\
& Incomplete emptying \\
\hline
\end{tabular}

prostate cancer by clinicians and patients alike, although there is no strong evidence for this [4]. Studies have found an increased risk of localised prostate cancer in men with LUTS, but no association between LUTS and advanced prostate cancer [20-22]. It is thought that patients presenting to their doctor with LUTS are at higher risk of being diagnosed with prostate cancer as a result of higher rates of testing, and are mainly diagnosed with early stage prostate cancer which may or may not affect their long-term mortality risk [21].

Other genito-urinary symptoms may also suggest that an undiagnosed prostate cancer is present. Visible haematuria is well established as a high-risk symptom for possible urological cancer, including prostate cancer $[23,24]$. Erectile dysfunction, another symptom that is very common in men and increases in prevalence with increasing age, has also been shown to be associated with prostate cancer $[25,26]$.

The majority of studies of prostate cancer diagnosis in symptomatic patients have been conducted in secondary care. They do not demonstrate any symptom that can distinguish prostate cancer from $\mathrm{BPH}$, but suggest that DRE and/or PSA may help to differentiate between the two [27]. A UK case-control study of primary care patients comparing men diagnosed with prostate cancer to age-matched controls showed that 
many individual LUTS (nocturia, hesitancy, frequency/urgency, and urinary retention) each had a positive predictive value (PPV) of $2.2-3.1 \%$, and impotence had a PPV of 3.0\% [26]. A risk of suspected cancer of $3 \%$ or more warrants referral for further investigation according to the National Institute for Health and Care Excellence (NICE) in the UK, meaning that many LUTS meet this threshold for prostate cancer.

DRE in the diagnosis of prostate cancer in primary care is also somewhat controversial, but has some stronger evidence for its use. Hamilton et al. [26] found a PPV of $12 \%$ (95\% CI 5.37) for an abnormal DRE deemed to be malignant by a GP, and a recently published systematic review of all studies of DRE for prostate cancer diagnosis in symptomatic patients in primary care found a pooled PPV of $42.3 \%$ [5]. This data suggests that, despite the reservations of some doctors in performing DREs, primary care clinicians can differentiate between a benign and malignant prostate on examination to a considerable extent.

Guidelines from the American Urological Association [28] and the European Association of Urology [29] focus on the role of PSA in the early detection of prostate cancer. The NICE guidance for 'Suspected cancer: recognition and referral' makes recommendations for clinicians to refer patients on the 'suspected cancer referral pathway' on the basis of symptoms, DRE findings, and/or PSA (Table 2).

\section{INVESTIGATIONS}

Debate continues around the role of PSA in the early detection and diagnosis of prostate cancer. As a screening test for prostate cancer in asymptomatic men, the three major trials to date have produced conflicting results (Table 3 ). All three studies show an increase in prostate cancer diagnosis in the intervention group, but only the European Randomised Study of Screening for Prostate Cancer (ERSPC) trial shows a reduction in prostate cancer mortality. None of the three trials showed a clear change in overall mortality, although there was some contamination of the control in the Prostate, Lung, Colorectal, and Ovarian (PLCO) study that might have affected the results [30]. Caution needs to be taken in comparing the Cluster

Table 2 Extract from the NICE suspected cancer: recognition and referral guidelines (NG12) 2015 [3]

1.6.1 Refer men using a suspected cancer referral pathway (for an appointment within 2 weeks) for prostate cancer if their prostate feels malignant on digital rectal examination

1.6.2 Consider a prostate-specific antigen (PSA) test and digital rectal examination to assess for prostate cancer in men with:

Any lower urinary tract symptoms, such as nocturia, urinary frequency, hesitancy, urgency or retention or

Erectile dysfunction or

Visible haematuria

1.6.3 Refer men using a suspected cancer referral pathway (for an appointment within 2 weeks) for prostate cancer if their PSA levels are above the age-specific reference range

Table 3 Summary table of major PSA screening trials

\begin{tabular}{llll}
\hline Trial & Population & $\begin{array}{l}\text { Prostate cancer diagnosis } \\
\text { rate ratio }(\mathbf{9 5 \%} \mathbf{C I})\end{array}$ & $\begin{array}{l}\text { Prostate cancer death } \\
\text { rate ratio }(\mathbf{9 5 \%} \text { CI) }\end{array}$ \\
\hline CAP, 2018 [33] & 415,357 UK men & $1.19(1.14,1.25)$ & $0.96(0.85,1.08)$ \\
PLCO, 2017 [34] & 76,683 US men & $1.22(1.16,1.29)$ & $1.04(0.87,1.24)$ \\
ERSPC, 2014 [35] & 182,160 European men & $1.57(1.51,1.62)$ & $0.79(0.69,0.91)$ \\
\hline
\end{tabular}


Table 4 Examples of patient decision aids for PSA testing

\begin{tabular}{|c|c|}
\hline Country & Decision aid \\
\hline \multirow[t]{6}{*}{ USA } & American Society of Clinical Oncology \\
\hline & 'Decision aid tool: Prostate cancer screening with PSA testing' \\
\hline & $\begin{array}{l}\text { https://www.asco.org/sites/new-www.asco.org/files/content-files/practice-and-guidelines/documents/2012-psa- } \\
\text { pco-decision-aid.pdf }\end{array}$ \\
\hline & Healthwise \\
\hline & 'Prostate cancer screening: Should I have a PSA test?' \\
\hline & https://www.healthwise.net/cochranedecisionaid/Content/StdDocument.aspx?DOCHWID=aa38144 \\
\hline \multirow[t]{3}{*}{ Australia } & Royal Australian College of General Practitioners \\
\hline & 'Should I have prostate cancer screening?' \\
\hline & https://www.racgp.org.au/download/Documents/Guidelines/prostate-cancer-screening-infosheetpdf.pdf \\
\hline \multirow[t]{3}{*}{ Europe } & Societe Internationale D’Urologie \\
\hline & 'PSA screening decision-making aid: For patients, general practitioners and urologists' \\
\hline & https://www.siuurology.org/themes/web/assets/files/society/psa_testing_brochure.pdf \\
\hline \multirow[t]{3}{*}{ UK } & Public Health England \\
\hline & 'PSA testing and prostate cancer: advice for well men aged 50 and over' \\
\hline & $\begin{array}{l}\text { https://assets.publishing.service.gov.uk/government/uploads/system/uploads/attachment_data/file/509191/ } \\
\text { Patient_info_sheet.pdf }\end{array}$ \\
\hline
\end{tabular}

Randomised Trial of PSA Testing for Prostate Cancer (CAP) trial to PLCO and ERSPC, as CAP used a one-off PSA screening test rather than regular PSA testing. A Cochrane review by Ilic et al., last updated in 2013, found no evidence for a reduction in prostate cancer mortality as a result of screening, and found that harms associated with PSA-based screening were common and could be severe [31]. The US Preventive Services Taskforce recommended against PSAbased prostate cancer screening for men over 70 years and or for men who do not express a preference for screening, but suggests that the decision to undergo screening with PSA should be an individual one for the patient after counselling from their doctor on the pros and cons of the test [2]. A recent consensus meeting of European experts recommended that limited prostate cancer screening should be rolled out [32].

PSA does have some utility for symptomatic patients as a marker of prostate cancer [36], although some caution is needed. PSA levels can be raised by a number of benign conditions, including $\mathrm{BPH}$, prostatitis, ejaculation, and exercise (false positive). PSA can be within the normal range for up to $25 \%$ of men with prostate cancer (false negative) [37]. Urine dipstick testing, with or without microscopy, culture and sensitivities (MC\&S) should be performed prior to PSA testing to rule out lower urinary tract infection [3]. Patients need to be made aware of the limitations of PSA, and the result needs to be considered in the wider context of the presence or absence of symptoms, the examination findings, and the patient's comorbidities and life expectancy. Using patient decision aids can support these discussions, and there is evidence to show that they improve men's knowledge of PSA, reduce decisional conflict/distress, and increase decisional satisfaction [38]. Table 4 includes some of the more commonly used PSA decision aids used in clinical practice. 
The current gold standard diagnostic test for prostate cancer is a prostate biopsy, usually via a transrectal (TRUS) or transperineal approach guided by ultrasound. Primary care clinicians suspecting prostate cancer after assessing a patient or finding an elevated PSA result should refer on a cancer pathway to their local urological service for diagnostic testing. Multiple cores from various regions of the prostate are taken and sent for histological analysis and tumour grading. This approach also has some limitations through missing some clinically significant prostate cancers and detecting some clinically insignificant cancers. Complications, such as haematuria and haematospermia, and infection as a result of biopsy are not uncommon [39].

\section{RISK PREDICTION MODELS}

Numerous risk prediction models and nomograms for calculating a man's risk of prostate cancer have been developed, including the Prostate Cancer Prevention Trial (PCPT) risk calculator [40] and the ERSPC risk calculator [41]. Louie and colleagues identified over 100 such models, and found that only six models predicting any prostate cancer (as opposed to clinically significant prostate cancer) had been thoroughly validated. None had been assessed for their effectiveness in clinical practice [42]. The vast majority of these risk calculators have been developed and validated using secondary care data [43, 44], and most attempt to predict biopsy outcome on the basis of pre-biopsy data. The European guidelines state that risk prediction models may be useful in reducing unnecessary biopsies on an individual case basis [29], and the US [28] and UK [45] guidelines make no mention of their utility in the early detection of prostate cancer.

\section{DIAGNOSTIC APPROACH IN PRIMARY CARE}

Examples of three common case scenarios are given in Fig. 1a-c.

\section{THE FUTURE}

A number of new tests and testing strategies are being trialled to improve the diagnosis of clinically significant prostate cancer. There is some evidence for mpMRI in a number of applications in prostate cancer. Recent studies suggest that mpMRI is more accurate in diagnosing prostate cancer compared to TRUS biopsy $[8,46]$; that mpMRI can improve the accuracy of biopsies of suspicious prostate lesions [47]; and mpMRI may be able to better distinguish between clinically significant and clinically insignificant prostate cancer [8]. Studies are currently underway to assess the utility of mpMRI in active surveillance for men with lowgrade, localised tumours [48]. All these studies so far have been conducted in secondary or tertiary level settings.

Blood-based biomarkers for prostate cancer are also being extensively investigated. The Stockholm3 model (STHLM3) is a risk-based model incorporating clinical data, DRE findings, plasma protein biomarkers (PSA, free PSA, intact PSA, hK2, MSMB, and M1C1), and 232 SNPs. In a Swedish population study, STHLM3 outperformed PSA alone in predicting clinically significant prostate cancer defined as Gleason grade of 7 or above [area under receiver operating characteristic curve (AUC) 0.74, 95\% CI $0.72-0.75$ vs $0.56,95 \%$ CI $0.55-0.60$ ] [49]. Validation studies of STHLM3 in other countries are ongoing. The $4 \mathrm{~K}$ test consists of four kallikrein proteins [total PSA, free PSA, intact PSA, and human kallikrein 2 (hK2)], and has also been shown to have applications in identifying clinically significant prostate cancer $[6,50,51]$.

\section{CONCLUSIONS}

Prostate cancer presents a number of challenges for primary care clinicians. Many men with prostate cancer are asymptomatic until the tumour has progressed, and common symptoms have significant crossover with benign conditions affecting the prostate. The disease is highly prevalent with a relatively lower mortality rate, necessitating the search for ways to identify clinically significant prostate cancer 


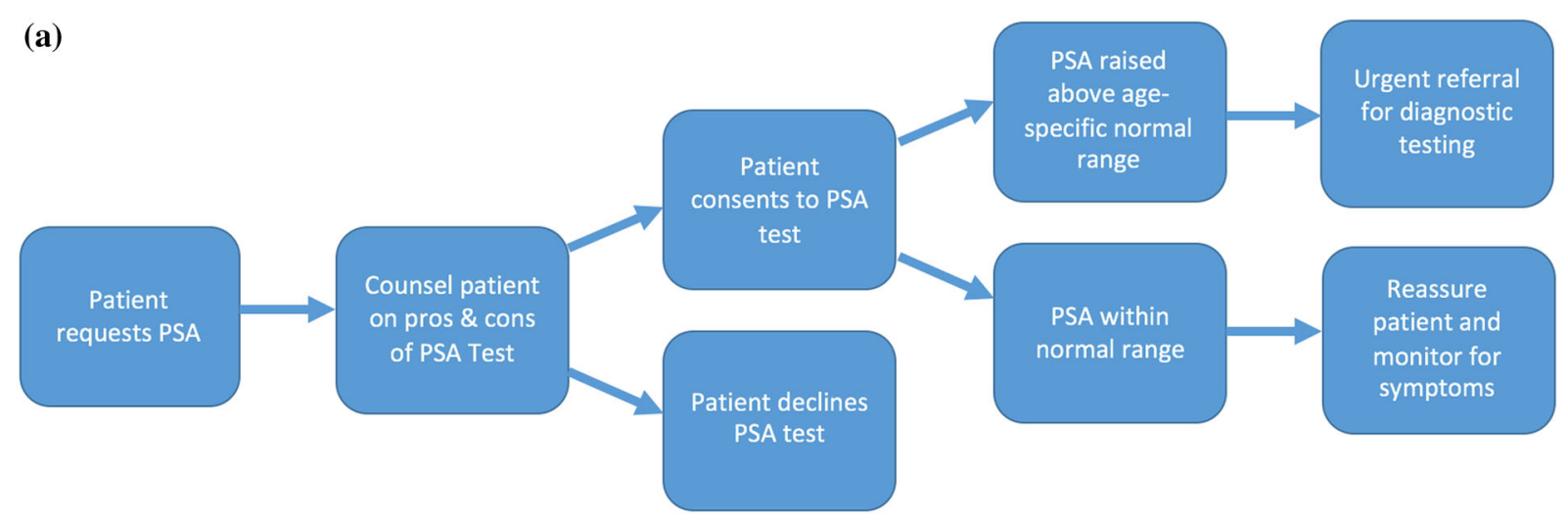

Scenario 1 - Asymptomatic male requesting PSA test for prostate cancer screening

(b)

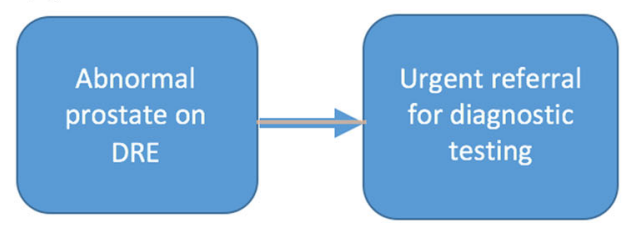

Scenario 2 - Incidental finding of abnormal prostate on DRE

(c)

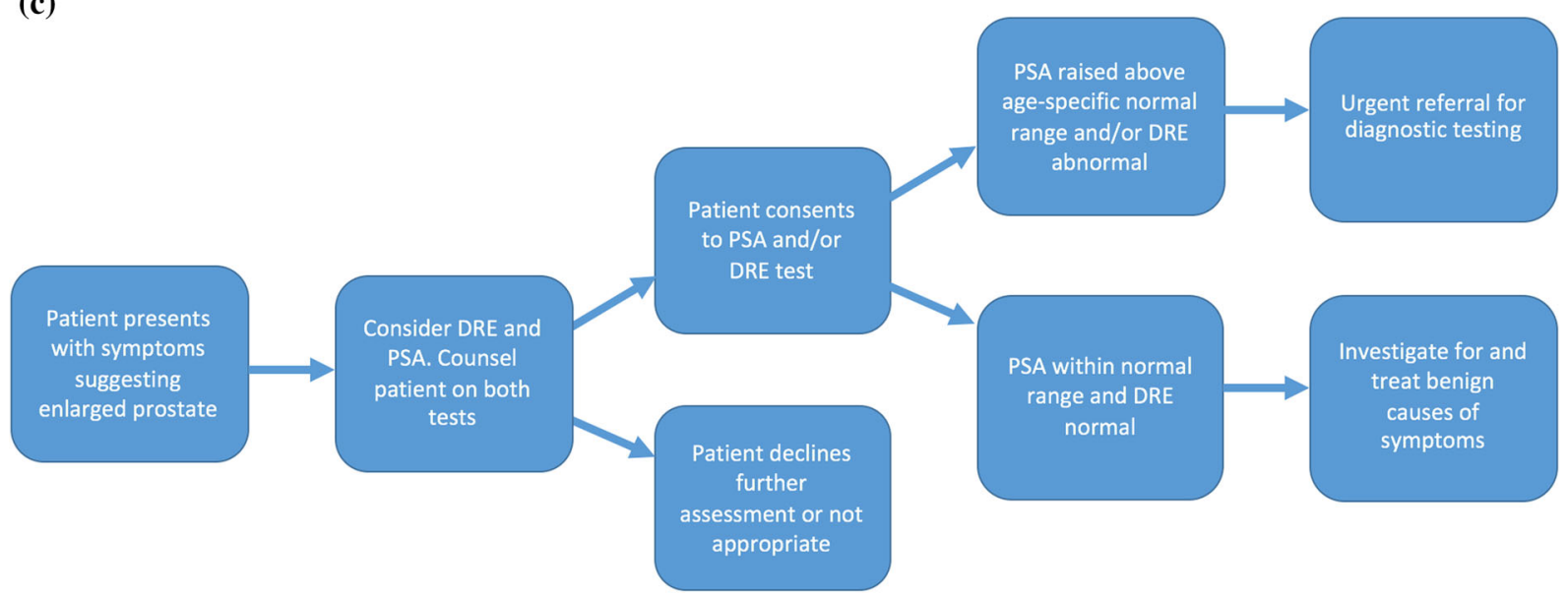

Scenario 3 - Patient presents with genito-urinary symptoms suggesting possible prostate cancer

Fig. 1 a Scenario 1-Asymptomatic man requesting PSA test for prostate cancer screening. b Scenario 2-Incidental finding of abnormal prostate on DRE. c Scenario 3-

requiring invasive treatment to improve survival. There are currently no widely available tests or strategies that have strong evidence for differentiating between clinically significant and clinically insignificant prostate cancer. Current diagnostic tests have limitations in terms of significant false positive and false negative rates. Research is ongoing into better methods for diagnosing prostate cancer.
Patient presents with genito-urinary symptoms suggesting possible prostate cancer

\section{ACKNOWLEDGEMENTS}

Funding. No funding or sponsorship was received for this study or publication of this article.

Authorship. All named authors meet the International Committee of Medical Journal 
Editors (ICMJE) criteria for authorship for this article, take responsibility for the integrity of the work as a whole, and have given their approval for this version to be published.

Disclosures. Samuel Merriel, Garth Funston and Willie Hamilton have nothing to disclose.

Compliance with Ethics Guidelines. This article is based on previously conducted studies and does not contain any studies with human participants or animals performed by any of the authors.

Open Access. This article is distributed under the terms of the Creative Commons Attribution-NonCommercial 4.0 International License (http://creativecommons.org/licenses/ by-nc/4.0/), which permits any noncommercial use, distribution, and reproduction in any medium, provided you give appropriate credit to the original author(s) and the source, provide a link to the Creative Commons license, and indicate if changes were made.

\section{REFERENCES}

1. Ferlay J, Soerjomataram I, Ervik M, et al. GLOBOCAN 2012 v1.0, Cancer Incidence and Mortality Worldwide: IARC CancerBase No. 11. International Agency for Research on Cancer, Lyon. 2013. http:// globocan.iarc.fr. Accessed 24 May 2018.

2. Grossman DC, Curry SJ, Owens DK, et al. Screening for prostate cancer: US Preventive services task force recommendation statement. JAMA. 2018;319(18):1901-13.

3. NICE. Suspected cancer: recognition and referral. 2015. p. 1-95. https://www.nice.org.uk/guidance/ ng12.

4. Østerø í Jákupsstovu J, Brodersen J. Do men with lower urinary tract symptoms have an increased risk of advanced prostate cancer? BMJ. 2018;361(1202):1-6. Available from https://www. bmj.com/content/bmj/361/bmj.k1202.full.pdf.

5. Jones D, Friend C, Dreher A, Allgar V, Macleod U. The diagnostic test accuracy of rectal examination for prostate cancer diagnosis in symptomatic patients: a systematic review. BMC Fam Pract. 2018;19:79.
6. Parekh DJ, Punnen S, Sjoberg DD, et al. A multiinstitutional prospective trial in the USA confirms that the 4Kscore accurately identifies men with high-grade prostate cancer. Eur Urol. 2015;68(3):464-70. https://doi.org/10.1016/j. eururo.2014.10.021.

7. Schumacher FR, Al Olama AA, Berndt SI, et al. Association analyses of more than 140,000 men identify 63 new prostate cancer susceptibility loci. Nat Genet. 2018;50:928-36. Available from http:// www.nature.com/articles/s41588-018-0142-8.

8. Ahmed HU, Bosaily AE-S, Brown LC, et al. Diagnostic accuracy of multi-parametric MRI and TRUS biopsy in prostate cancer (PROMIS): a paired validating confirmatory study. Lancet. 2017;380:1-8. https://doi.org/10.1016/S0140-6736(16)32401-1.

9. Wong MCS, Goggins WB, Wang HHX, et al. Global incidence and mortality for prostate cancer: analysis of temporal patterns and trends in 36 countries. Eur Urol. 2016;70(5):862-74. https://doi.org/10. 1016/j.eururo.2016.05.043.

10. ONS. Cancer registration statistics, England: 2014. 2016;1-17. https://www.ons.gov.uk/peoplepopulation andcommunity/healthandsocialcare/conditionsand diseases/bulletins/cancerregistrationstatisticsengland/ 201.

11. Kiciński M, Vangronsveld J, Nawrot TS. An epidemiological reappraisal of the familial aggregation of prostate cancer: a meta-analysis. PLoS One. 2011;6(10):1-7.

12. Fachal L, Gõmez-Caamaño A, Celeiro-Muñoz C, et al. BRCA1 mutations do not increase prostate cancer risk: results from a meta-analysis including new data. Prostate. 2011;71(16):1768-79.

13. Leongamornlert $\mathrm{D}$, Mahmud $\mathrm{N}$, Tymrakiewicz $\mathrm{M}$, et al. Germline BRCA1 mutations increase prostate cancer risk. Br J Cancer. 2012;106(10):1697-701.

14. Ryan S, Jenkins MA, Win AK. Risk of prostate cancer in lynch syndrome: a systematic review and metaanalysis. Cancer Epidemiol Biomarkers Prev. 2014;23(3):437-49.

15. Lloyd T, Hounsome L, Mehay A, Mee S, Verne J, Cooper A. Lifetime risk of being diagnosed with, or dying from, prostate cancer by major ethnic group in England 2008-2010. BMC Med. 2015;13(1):1-10. https://doi.org/10.1186/s12916-015-0405-5.

16. Evans S, Metcalfe C, Ibrahim F, Persad R, BenShlomo Y. Investigating Black-White differences in prostate cancer prognosis: a systematic review and meta-analysis. Int J Cancer. 2008;123(2):430-5. 
17. Ben-Shlomo Y, Evans S, Ibrahim F, et al. The risk of prostate cancer amongst black men in the United Kingdom: the PROCESS Cohort Study. Eur Urol. 2008;53(1):99-105.

18. Sakr W, Haas G, Cassin B, Pontes J, Crissman J. The frequency of carcinoma and intraepithelial neoplasia of the prostate in young male patients. J Urol. 1993;150:379-85.

19. Rosen R, Altwein J, Boyle P, et al. Lower urinary tract symptoms and male sexual dysfunction: the multinational survey of the aging male (MSAM-7). Eur Urol. 2003;44(6):637-49.

20. Martin RM, Vatten L, Gunnell D, Romundstad P, Nilsen TIL. Lower urinary tract symptoms and risk of prostate cancer: the HUNT 2 cohort, Norway. Int J Cancer. 2008;123(8):1924-8.

21. Whellan DJ, Ellis SJ, Kraus WE, et al. The effect of benign lower urinary tract symptoms on subsequent prostate cancer testing and diagnosis. Eur Urol. 2013;63(6):1021-7.

22. Bhindi A, Bhindi B, Kulkarni GS, et al. Modern-day prostate cancer is not meaningfully associated with lower urinary tract symptoms: analysis of a propensity score-matched cohort. J Can Urol Assoc. 2017;11(1-2):41-6.

23. Bruyninckx R, Buntinx F, Aertgeerts B, Van Casteren $\mathrm{V}$. The diagnostic value of macroscopic haematuria for the diagnosis of urological cancer in general practice. Br J Gen Pract. 2003;53(486):31-5.

24. Gan JH, Harris AC, Green JSA. Quantifying the risk of malignancy in patients with visible haematuria presenting to the emergency department. J Clin Urol. 2015;8(2):132-8.

25. Lin W-Y, Chang Y-H, Lin C-L, Kao C-H, Wu H-C. Erectile dysfunction and the risk of prostate cancer. Oncotarget. 2017;8(32):52690-8. Available from http://www.oncotarget.com/fulltext/17082.

26. Hamilton W, Sharp DJ, Peters TJ, Round AP. Clinical features of prostate cancer before diagnosis: a population-based, case-control study. $\mathrm{Br} \mathrm{J}$ Gen Pract. 2006;56(531):756-62. Available from http:// www.pubmedcentral.nih.gov/articlerender. fcgi?artid=1920715\&tool=pmcentrez\&rendertype= abstract.

27. Hamilton W, Sharp D. Symptomatic diagnosis of prostate cancer in primary care: a structured review. Br J Gen Pract. 2004;54(505):617-21. Available from http://www.pubmedcentral.nih.gov/articlerender. fcgi?artid=1324845\&tool=pmcentrez\&rendertype $=$ abstract.
28. Carter B, Albertsen P, Barry M, et al. Early detection of prostate cancer: AUA guideline. Linthicum: American Urological Association Education and Research; 2018. p. 1-28.

29. Mottet N, Bellmunt J, Briers E, et al. EAU-ESTRO-ESUR-SIOG guidelines on prostate cancer. European Association of Urology. 2017. Available from https://uroweb.org/wp-content/uploads/09Prostate-Cancer_2017_web.pdf.

30. de Koning HJ, Gulati R, Moss SM, et al. The efficacy of prostate-specific antigen screening: Impact of key components in the ERSPC and PLCO trials. Cancer. 2017. https://doi.org/10.1002/cncr.31178.

31. Ilic D, Neuberger MM, Djulbegovic M, Dahm P. Screening for prostate cancer. Ilic D, editor. Cochrane Database Syst Rev. 2013 Sep $1 ;(1): C D 004720 . \quad$ https://doi.org/10.1002/ 14651858.cd004720.pub3\%5cn

32. Heijnsdijk EAM, Bangma $\mathrm{CH}$, Borràs $\mathrm{JM}$, et al. Summary statement on screening for prostate cancer in Europe. Int J Cancer. 2018;142(4):741-6.

33. Martin RM, Donovan JL, Turner EL, et al. Effect of a low-intensity PSA-based screening intervention on prostate cancer mortality: the CAP randomized clinical trial. JAMA. 2018;319(9):883-95.

34. Pinsky PF, Prorok PC, Yu K, et al. Extended mortality results for prostate cancer screening in the PLCO trial with median follow-up of 15 years. Cancer. 2017;123(4):592-9.

35. Schröder FH, Hugosson J, Roobol MJ, et al. Screening and prostate cancer mortality: results of the European Randomised Study of Screening for Prostate Cancer (ERSPC) at 13 years of follow-up. Lancet. 2014;384(9959):2027-35. Available from http://linkinghub.elsevier.com/retrieve/pii/ S0140673614605250.

36. Vedanayagam M, Kumar A, Madaan S. Lower urinary tract symptoms in an older man. BMJ. 2017;357:j1493.

37. Schmid HP, Prikler L, Sturgeon CM, Semjonow A. Diagnosis of prostate cancer: the clinical use of prostate specific antigen. EAU Update Ser. 2003;1(1):3-8.

38. Ilic D, Jammal W, Chiarelli P, et al. Assessing the effectiveness of decision aids for decision making in prostate cancer testing: a systematic review. Psychooncology. 2015;24(10):1303-15.

39. Loeb S, Vellekoop A, Ahmed HU, et al. Systematic review of complications of prostate biopsy. Eur Urol. 2013;64(6):876-92. https://doi.org/10.1016/j. eururo.2013.05.049. 
40. Thompson IM, Ankerst DP, Chi C, et al. Assessing prostate cancer risk: results from the prostate cancer prevention trial. J Natl Cancer Inst. 2006;98(8):529-34. https://doi.org/10.1093/jnci/ djj131.

41. Kranse R, Roobol M, Schröder FH. A graphical device to represent the outcomes of a logistic regression analysis. Prostate. 2008;68(15): 1674-80.

42. Louie KS, Seigneurin A, Cathcart P, Sasieni P. Do prostate cancer risk models improve the predictive accuracy of PSA screening? A meta-analysis. Ann Oncol. 2015;26(5):848-64. https://doi.org/10.1093/ annonc/mdu525.

43. Poyet C, Nieboer D, Bhindi B, et al. Prostate cancer risk prediction using the novel versions of the European Randomised Study for Screening of Prostate Cancer (ERSPC) and Prostate Cancer Prevention Trial (PCPT) risk calculators: independent validation and comparison in a contemporary Europe. BJU Int. 2016;117(3):401-8. https://doi.org/10. 1111/bju.13314.

44. Ankerst DP, Straubinger J, Selig K, et al. A contemporary prostate biopsy risk calculator based on multiple heterogeneous cohorts. Eur Urol. 2018;74(2):197-203. https://doi.org/10.1016/j. eururo.2018.05.003.

45. NICE. Prostate cancer: diagnosis and management. London: National Institute for Health and Clinical Excellence; 2014. https://www.nice.org.uk/ guidance/cg175/resources/prostate-cancerdiagnosis-and-management-pdf-35109753913285. Accessed 20 June 2018.
46. Boesen L, Norgaard N, Logager V, et al. Assessment of the diagnostic accuracy of biparametric magnetic resonance imaging for prostate cancer in biopsynaive men: the biparametric MRI for detection of prostate cancer (BIDOC) study. JAMA Netw Open. 2018;1(2).

47. Kasivisvanathan V, Rannikko AS, Borghi M, et al. MRI-targeted or standard biopsy for prostate-cancer diagnosis. N Engl J Med. 2018. https://doi.org/10. 1056/NEJMoa1801993.

48. Meng X, Rosenkrantz AB, Taneja SS. Role of prostate magnetic resonance imaging in active surveillance. Transl Androl Urol. 2017;6(3):444-52. Available from http://tau.amegroups.com/article/ view/15159/15452.

49. Gronberg H, Adolfsson J, Aly M, et al. Prostate cancer screening in men aged 50-69 years (STHLM3): a prospective population-based diagnostic study. Lancet Oncol. 2015;16(16):1667-76. https://doi.org/10.1016/S1470-2045(15)00361-7.

50. Sjoberg DD, Vickers AJ, Assel M, et al. Twenty-year risk of prostate cancer death by midlife prostatespecific antigen and a panel of four kallikrein markers in a large population-based cohort of healthy men. Eur Urol. 2018;73(6):941-8. https:// doi.org/10.1016/j.eururo.2018.02.016.

51. Lin DW, Newcomb LF, Brown MD, et al. Evaluating the four kallikrein panel of the $4 \mathrm{~K}$ score for prediction of high-grade prostate cancer in men in the canary prostate active surveillance study. Eur Urol. 2017;72(3):448-54. https://doi.org/10.1016/j. eururo.2016.11.017. 